المجلة الدولية للدراسات التربوية والنفسية e-ISSN 2520-4149, p-ISSN 2520-4130

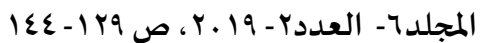
https://doi.org/DOI:10.31559/EPS2019.6.2.1
المجلة الدولية للدراسات

الثربوية والثفسية

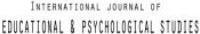

رفاد للدراسات والأبحاث www.refaad.com

\title{
اضطراب صورة الجسم وعلاقته بالشعور بالاكتئاب لدى عينة من مرضى السكري
}

\section{لولوة صالح الرشيد}

أستاذ الصحة النفسية المشارك- قسم علم النفس- كلية التربية- جامعة القصيم- المملكة العربية السعودية

هدفت الدراسة الحالية إلى الكشف عن العلاقة بين اضطراب صورة الجسم والشعور بالاكتئاب لدى عينة من مرضى السكري وقد تكونت

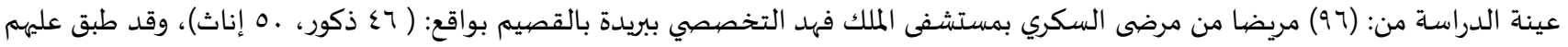

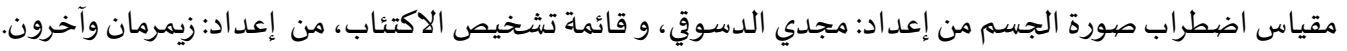
أظهرت نتائج الدراسة وجود علاقة ارتباطية دالة بين اضطراب صورة الجسم وبين الشعور بالاكتئاب، كما أظهرت النتائج أن الإناث أكثر

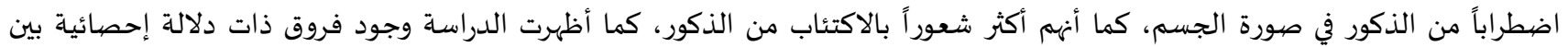
متوسطات درجات أفراد عينة الدراسة (ذكور- إناث)، من مرضى السكري على مقياس اضطراب صورة الجسم وقائمة الاكتئاب والذي يرجع بدوره لاختلاف العمر بين أفراد عينة الدراسة.

الكلمات المفتاحية: اضطراب صورة الجسم؛ الاكتئاب ؛مرض السكري.

\section{(1) (1)}

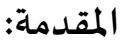

إن الاهتمام بصورة الجسم يعتبر مكوناً أساسياً، من مكونات شخصية الإنسان وهو بمثابة الصورة الذهنية عن أجسامنا ولا شك، أن

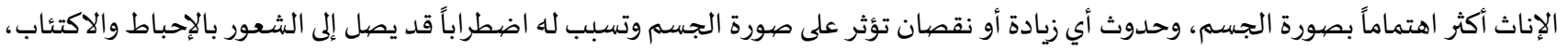

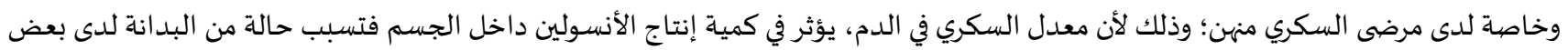

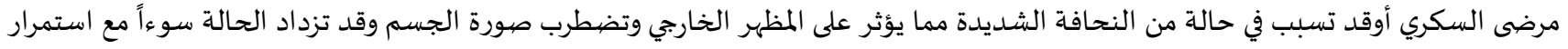

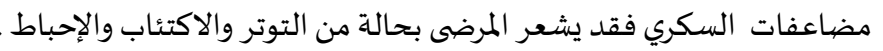

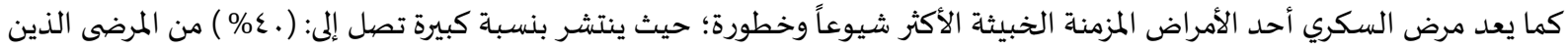

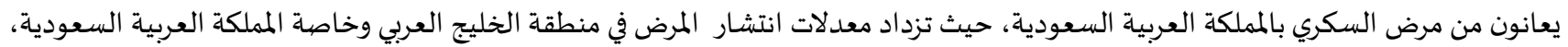
حسب تقرير منظمة الصحة العالمياة كما أن له عدة آثار جسمية، ونفسية خطيرة ،تحتاج إلى توعية المرضى بتلك الآثار ؛ حتى يصبح لدهيه لدهيه الوعي الكافي

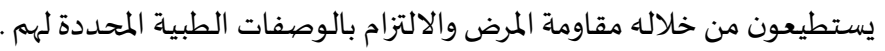
وبالرغم من التقدم العلمي، في علاج مرض السكري إلا أنه مازالت لدى المرضى معاناة نتيجة لأعراض السكري ومضاعفاته وتأثيره على جميع أجهزة الجسم. ويري جاكسون (Jackson,1995:20) أن مظهر الجسم يعد جانباً مهما من جوانب الحياة، ويتمثل في تفاعلات الآخرين وردود أفعالهم تجاه جسم أي منها وكذلك عندما نتفاعل مع العالم الاجتماعي المحيط بنا.

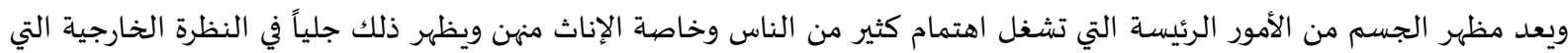
تختص بالتأثيرات الاجتماعية للمظهر الخارجي.

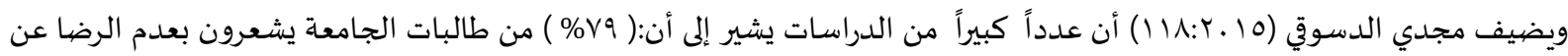

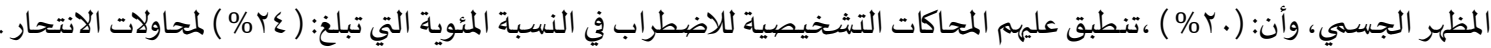

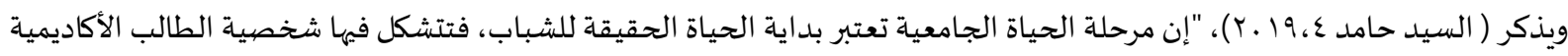
ويتم فطامه عن سلوكه الطفولي والانتقال للتوافق مع متطلبات الحياة الجامعية ويبدأ في التواصل مع البيئة الجديدة. وتعتبر بيئة الجامعة هي الأساس

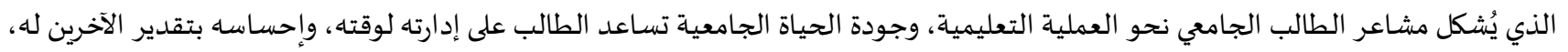


وعدم انفصاله بالاغتراب النفسي عن البيئة الجامعية خاصيةٍ أن معظم الجامعات الأم كجامعة الملك سعود تكون بالعاصمة أي بمدينة غالباً تختلف

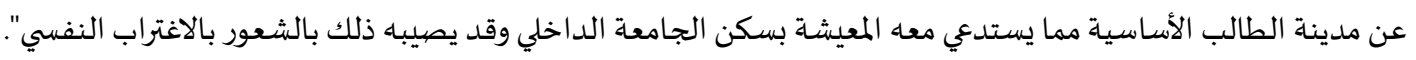
ويذكر فيلبس،(Phillips,1999:142) أن معظم الأفراد الذين يعانون من اضطراب صورة الجسم يظلون صامتين ولا يفصحون عن

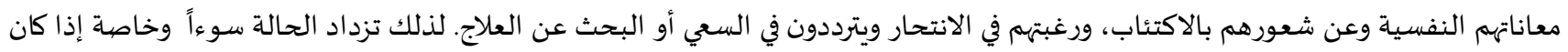

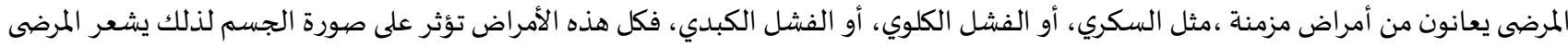

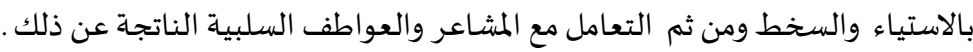

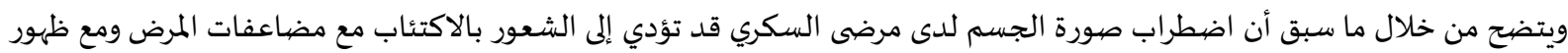

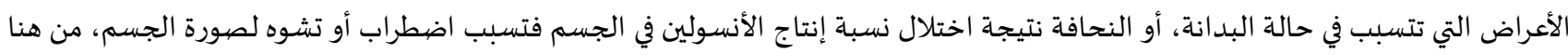
جاء اهتمام الباحثة بدراسة العلاقة بين اضطراب صورة الجسم والشعور بالاكتئاب لدى مرضى السكري.

مشكلة الدراسـة:

نبعت مشكلة الدراسة من خلال اطلاع الباحثة ومتابعتها لزيادة أعداد مرضى السكري في المملكة العربية السعودية وخاصة ،من خلال

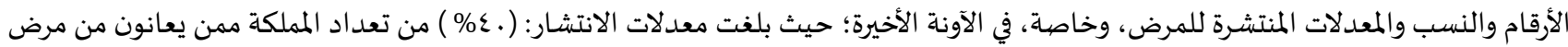

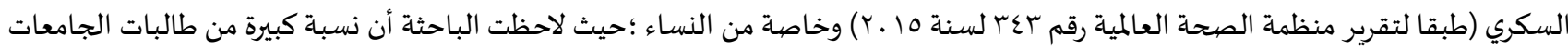
يعانون من مرض السكري؛ بذلك تولد لدى الباحثة الإحساس بمشكلة الدراسة كما تتلخص مشكلة الدراسة في الإجابة على التساؤلات الآتية:

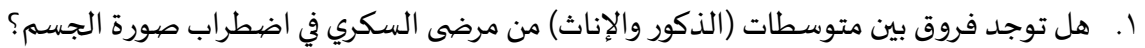

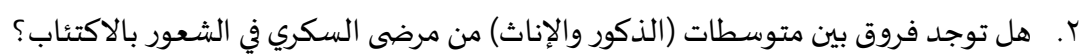

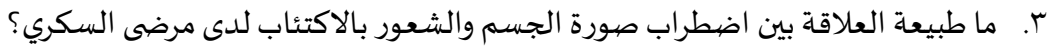

أهمية الدراسـة: ا. أمساعدة في تقديم الدعم النفسي والمعنوي لمرضهى السكري.

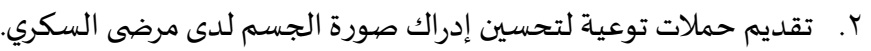

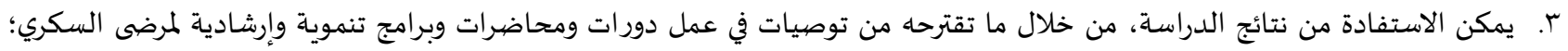

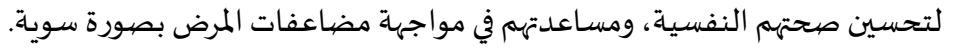

أهداف الدراسـة: تهدف الدراسة الحالية إلى ما يأتي: ا. الكشف عن طبيعة العلاقة بين اضطراب صورة الجسم، وعلاقته بالشعور بالاكتئاب لدى مرضى السكري.

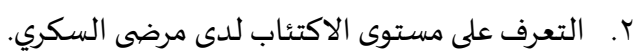
r. التعرف على مستوى اضطراب صورة الجسم لدى مرضى السكري.

$$
\text { مصطلحات الدراسـة: }
$$

• اضطراب صورة الجسم: Body-image Disturbances

يقصد باء الانشغال الزائد في الحد عن صورة الجسم و المظهر الخارجي والشعور بوجود بعض العيوب في المظهر الجسمي وهو الصورة الذهنية

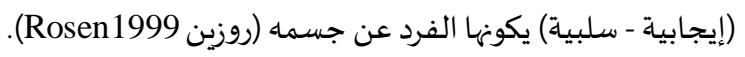

Depression : الاكتئاب:

هو اضطراب نفسي يصاحبه مجموعة من الأعراض الإكلينيكة التي توضح الحالة النفسية والمزاجية للفرد والتي تتمثل في الحزن الشديد والإحباط،

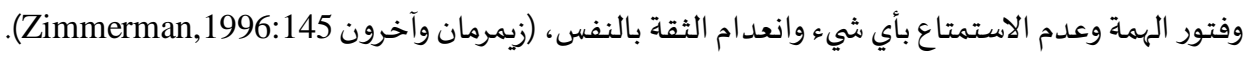

Diabetes: مرض السكري

هو مرض يرتفع فيه مستوى السكر في الدم عن المعدل الطبيعي نتيجة نقص كلي أو جزئي في إنتاج هرمون الأنسولين من خلايا البنكرياس وله

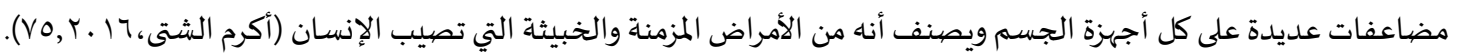


أولاً: اضطراب صهورة الجسم:

اضطراب صورة الجسم هو انشغال زائد عن الحد أو انشغال بصورة الجسم وهو من الأمور التي تسبب صعوبة في التشخيص و التمييز بين

الحالة النفسية المرضية وبين الانشغالات المادية والطبيعية بشأن المظهر. وينمو اضطراب صورة الجسم من خلال الاستعدادات البيولوجية؛ حيث يحدث الد افع البيولوجي المتزايد نحو الناحية الجمالية فيما يتعلق بالتناسق في مظهر الجسم كما تلعب التعليقات أو المضايقات من جانب الآخرين دوراً فعَّالاً في ظهور هذا الاضطراب، بالإضافة إلى ظهور الأمراض التي

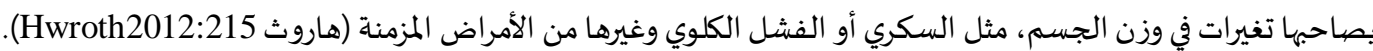
بدأ الاهتمام بالدراسة النظرية لمفهوم صهورة الجسم، منذ القرن العشرين، وظهر في أعمال (سكليدر مفهوم صورة الجسم كمحدد للتوافق النفسي و الاجتماعي للفرد في مجال علم النفس بصفة عامة وعلم النفس الإكلينيكي بصفة خهام خاصة.

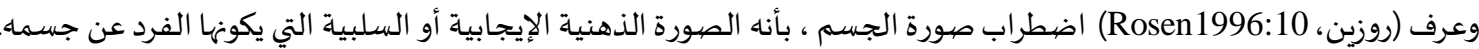

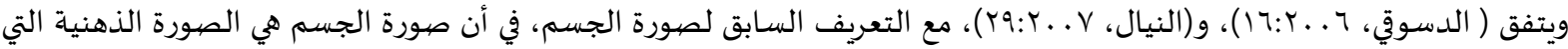
يكونها الفرد عن جسمه ككل بما فيها من خصائص فيزيقية ووظيفية والتي بالتبعية تسهم في تقييماه لذاته كما يؤدي التقدير السلبي لتلك الصهورة إلى في إنى ظهور اضطراب في صورة الجسم.

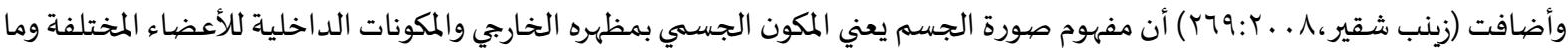
يصاحب ذلك من مشاعر واتجاهات موحية نحو صورة الجسم أما إذا ظهرت مشاعر واتجاهات سلبية فسوف يظهر معها اضطراب في صورة الجسم

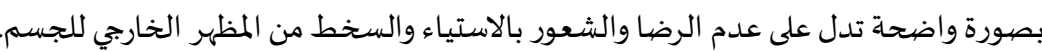
مكونات صورة الجسم كما صنفها جوف (Gove,2009:128) هي كالتالي: ا. الجاذبية الجسمية. r. التناسق بين مكونات الوجها الظاهرية.

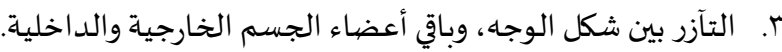
ع. المظهر الشخصي العام. 0. ألتاسق بين الجسم وشكله ومستوى التفكير. كما أشار (فاندن بوس، Vanden Bos, 2008:520) ، إلى مكونات صورة الجسم على النحو التهو التالي: ا. . مكون إدراكي معرفي، يرتبط بالتفكير الدقيق لحجم الجسم.

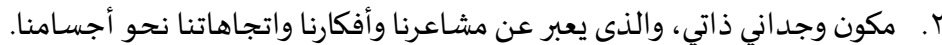
r. مكون سلوكي، يشير إلى سلوك الفحص الذاتي المتكرر للجسم، والرغبة في تجنب المواقف التي تجعلنا نشعر بعدم الراحة في الجسم. كما أشار بعض الباحثين، إلى وجود ثلاثة أبعاد يدور حولها مفهوم صورة الجسمه، وهي على الفي النحو التالي: ا. الأساس الفسيولوجي، وهو الإحساسات الصاعدة للمخ في وضع الجسم وأجزائه وشكله والتناسق العضلي بين أجزائه وأي خلل يسبب اضطراب

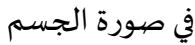
r. البناء الجنسي، ويشتمل على موضوعات الافتتان بالنفس والجاذبية الجنسية والاهتمام الجمالي بالجسم من خلال الملابس وأنماط الزينة الأخرى وأي تشوه يسبب اضطراباً. r. الأساس الاجتماعي، ويحتوى على الموضيوعات الاجتماعية المرتبطة بالجسم، مثل الخوف من الخجل، وصهورة الجسم لدى الآخرين وأي قصهور

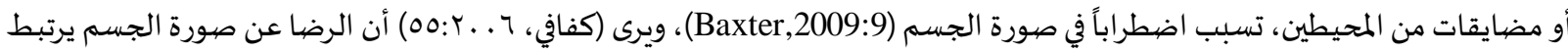

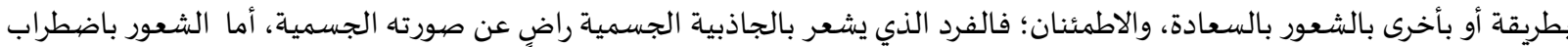
صورة الجسم فهو مرتبط بالشعور بالخجل، وعدم الرضا، والاستياء، وقد يصل إلى الاكتئاب والتفكير في الانتحار.

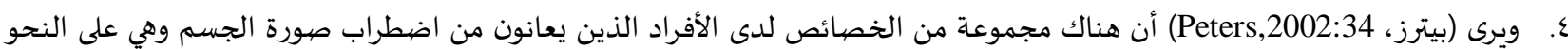

ا. يشعرون بمجموعة مختلطة من الانفعالات، مثل الشعور بالاشمئزاز من صورة الجسم.

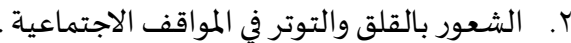
r. إنعانون من أمراض الاكتئاب نتيجة للعزلة الاجتماعية. 


$$
\begin{aligned}
& \text { ع. يعانون من الإحباط والاستياء، وفقدان المتعة بالحياة. } \\
& \text { 0. يبالغون في الاهتمام بالمظهر الخارياري. } \\
& \text { النظريات المفسرة لاضطراب صورة الجسم وهي النظريات الثلاث الآتياة: }
\end{aligned}
$$

ا. النظرية الاجتماعية الثقافية: Sociocultural theory

وتعتمد هذه النظرية على المستويات الاجتماعية للجمال، التي تؤكد في المقام الأول على الرغبة في النحافة والرشاقة، على اعتبار أن النحافة

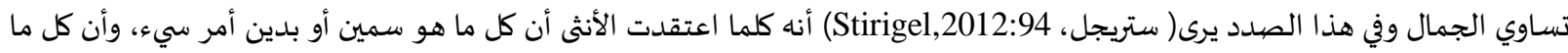
هو نحيف أمر جميل كلما اتجهت نحو النحافة، وكلما ازداد توترها وشعورها بالاكتئاب وأصببحت مهمومة بشأن البدانة.

r. نظرية التباين أو التعارض بين الذات وبين المثل الأعلى: Self. ideal Discrepancy theory

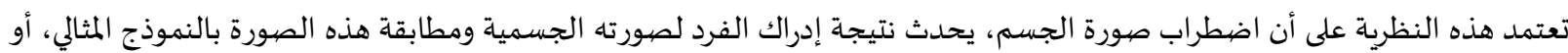

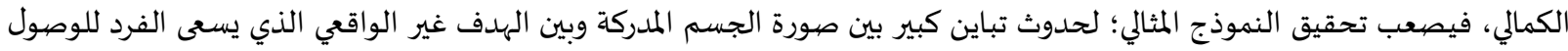

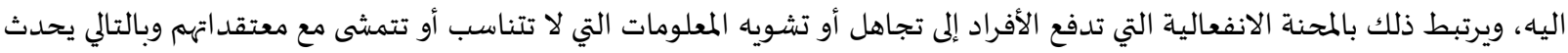

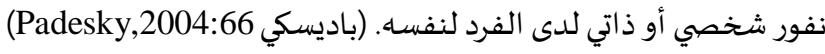

r. نظرية الفشل التكيفي: Adaptive Failvre theory

ويعتمد هذا المنحى على اعتبار أن اضطراب صورة الجسم، هو اضطراب يرجع السبب الرئيسي فيه إلى فشل الفرد في التكيف مع الأخرين،

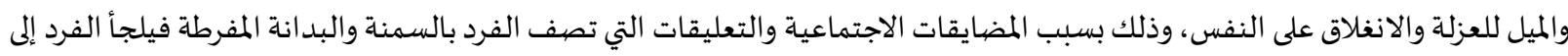
البعد عن الآخرين وينغمس في العزلة حتى يفشل في التكيف في مواجهة الأخرين ويشعر بعدم الرغبة في مقابلة الأخرين الذين يعرفون الفرد؛

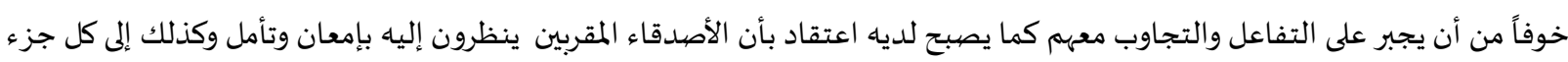

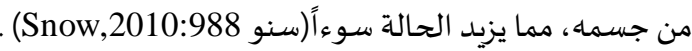

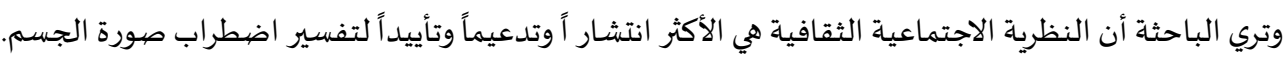

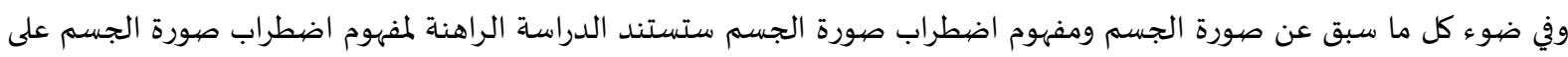

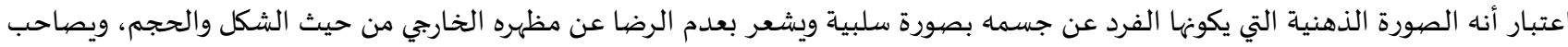

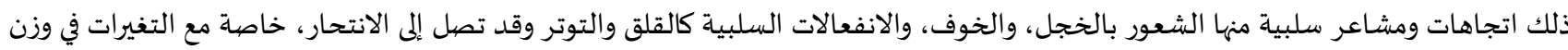

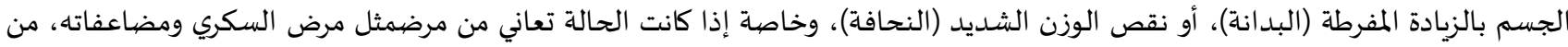

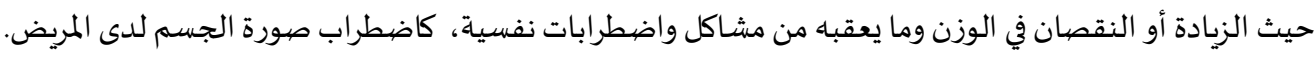

ثانياً: الشعور بالاكتئاب:

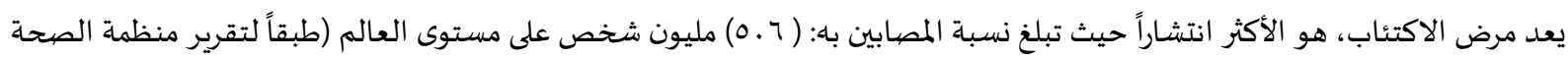
العالمية رقم 97 لسنة با •r)، ويرى (ويسي، Weisse,2002:406) أن الاكتئاب بمعناه الواسع يشير إلى مزاج عسير ويتميز بمشاعر الحزن العميق وافتقاد العون والشعور بالوحدة النفسية .

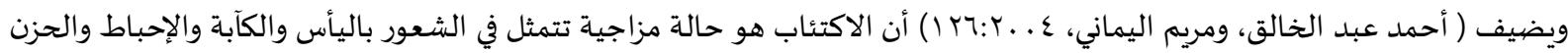
الشديد وانقباض الصبدر.

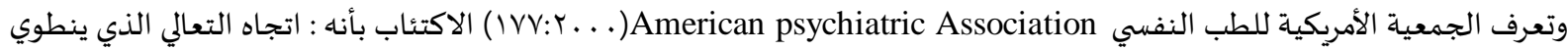
على الشعور بعدم الكفاية، وفقدان الأمل يصحبه انخفاض في النشاط الجسمي والنفسي، واغتمام من المستقبل، والحط من قدر النفس وتوهمات

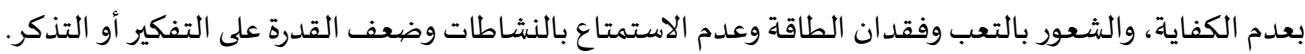

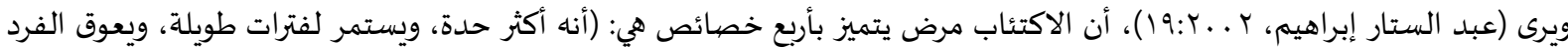

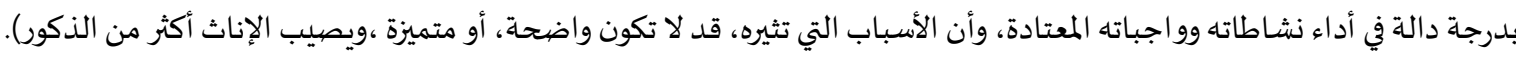
أسباب الاكتئاب:

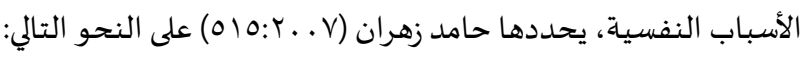
1. التوتر الانفعالي والظروف المحزنة والخبرات الأليمة. r. الكوارث القاسية، (كموت عزيز أو طلاق أو سجن بريء). r. الحرمان، وفقدان الحب، والاهتمام والمساندة الاجتماعية. ع. الإحباط والفشل والشعور بخيبة الأمل. 


$$
\begin{aligned}
& \text { 0. التربية الخاطئة والخبرات الصيادمة. }
\end{aligned}
$$

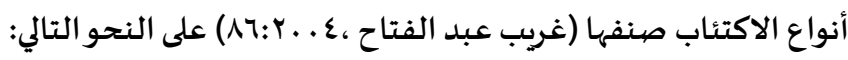

$$
\begin{aligned}
& \text { 1. اكتئاب خفيف:وهو أخف صور الاكتئاب. } \\
& \text { r. اكتئاب حاد :وهو أشد صهور الاكتئاب. } \\
& \text { r. اكتئاب مزمن: وهو دائم وليس مناسبة فقط. }
\end{aligned}
$$

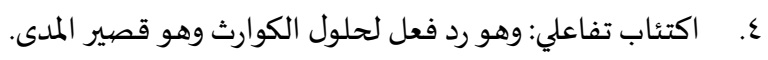

$$
\begin{aligned}
& \text { 0. اكتئاب القعود: وهو نتيجة الإحالة للتعاقد والمعاش. }
\end{aligned}
$$

أعراض الاكتئاب:

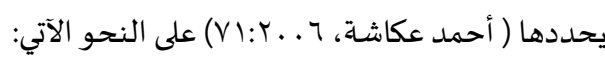
أولاً: أعراض جسمية: مثل انقباض الصدر، والشعور بالضيق، وفقدان الشهية، والصداع والخمول والألم، خاصة بالظهر ،والصداع والتعب لأقل مجهود، وضعف النشاط العام، وتوهم المرض.

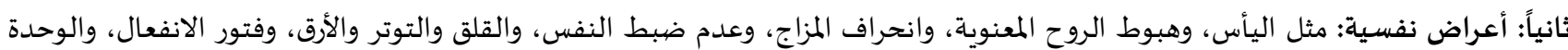

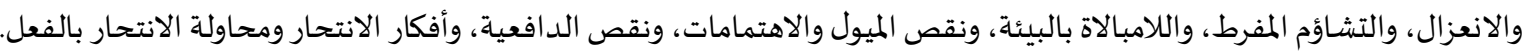

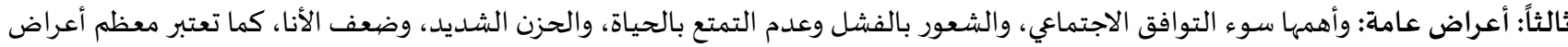

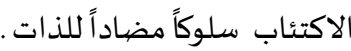
وترى الباحثة أن الاكتئاب هو: خبرة إنسانية عامة، يمر بها كل فرد تقريباً خلال مرحلة من مراحل عمره بعرض أو آخر ولكن هذه الخبرة

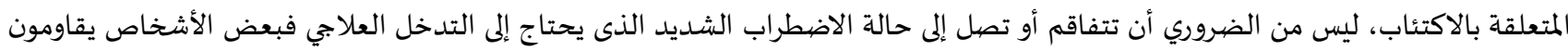

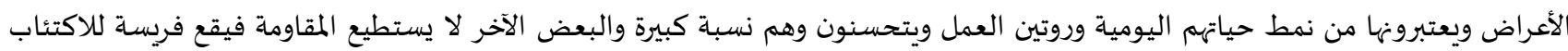

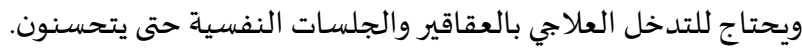

ثالثاً: مرض السكري:

يعتبر مرض السكري من الأمراض المزمنة التي تصيب الإنسان بسبب خلل في هرمون الأنسولين أو لعدم تقبل الأنسجة له؛؛ مما يؤدي إلى

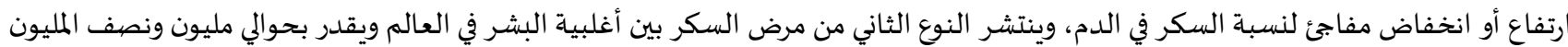

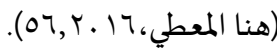
تعريف مرض السكري:

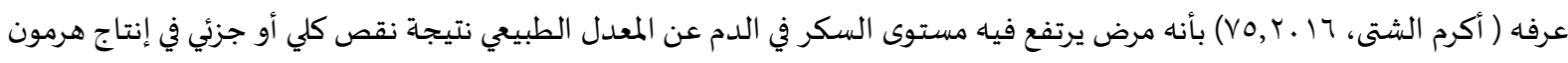
الأنسولين من خلايا البنكرياس، وله مضاعفات عديدة على كل أجهزة الجسم، ويصنف من الأمراض المزمنة الخبيثة التي تصيب الإنسان.

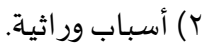

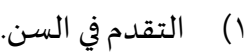

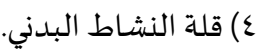

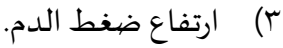

$$
\begin{aligned}
& \text { 7) الإصيابة بإحدى أمراض الأوعية الدموية. } \\
& \text { 0) ارتفاع مستوى الكولسترول الضيار. }
\end{aligned}
$$

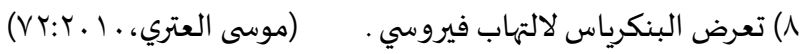

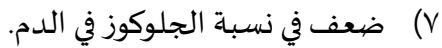

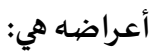

$$
\begin{aligned}
& \text { r) التوتر الشديد والعصبية المستمرة. } \\
& \text { () ضعف الجسم بشكل كبير. } \\
& \text { ع) زيادة الإصابة بتصلب الشرايين. } \\
& \text { r) جفاف حاد في الفم والحلق. }
\end{aligned}
$$

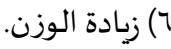

$$
\begin{aligned}
& \text { 0) الذبحات الصيدرية وأمراض الكلى. }
\end{aligned}
$$

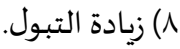

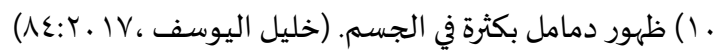

$$
\begin{aligned}
& \text { V) فقدان الإحساس بالأطراف. } \\
& \text { 9) خلل وتشوش في الرؤية . }
\end{aligned}
$$

مضاعفات مرض السكري على أجهزة الجسهم: للسكري مضاعفات طويلة المدى ومنها: 
ا. إصابة الأعصاب: يرى الباحثون أن السبب في إصابة الأعصاب يرجع إلى زيادة نسبة السكر في الدم والذي يضر الأوعية الدموية التي تغذي الأعصاب

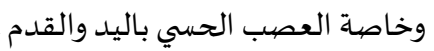
r. إصابة الكلى: تقوم الكلى بعملية تصفية الفضلات في الدم، وإخراجها في البول، وذلك عن طريق ملايين من الأوعية الدموية الدقيقة ولكن يؤدي مرض السكر إلى إصابة وتدمير هذه العملية. r. إصابة العين: يؤدي مرض السكر إلى تلف في الأوعية الدموية لشبكة العين، ويتسبب ذلك في الإصابة بالمياه البيضاء أو الزرقاء بالعين التي تحدث مشاكل خطيرة للعين. ع. إصابة القلب والأوعية الدموية: يرفع مرض السكر فرصية الإصابة بأمراض القلب والأوعية الدموية بشكل تدريجي، وتتضمن (أمراض الشرايين، آلام

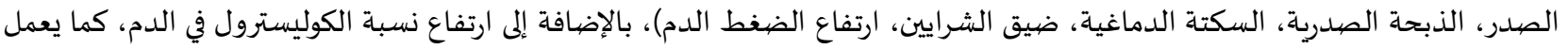
مرض السكر ،على ضعف جهاز المناعة بالجسم ويزيد من فرص الإصابة بالعديد من الفيروسات. المضاعفات قصيرة المدى:

ولمرض السكر مضاعفات قصيرة المدى مثل الانخفاض المفاجئ للسكر في الدمن فيصل إلى (.7) مليجرام/عشر لتر، فيسبب غيبوبة

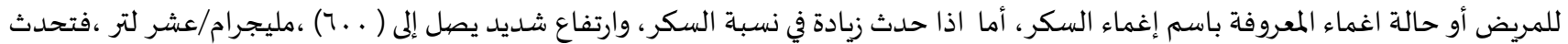

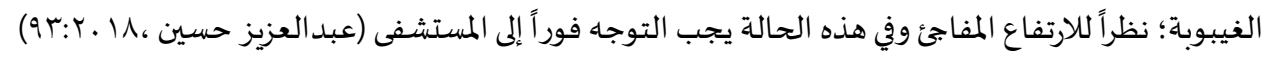
علاج مرض السكري: يحتاج مريض السكري إلى المتابعة والالتزام بالعقاقير، ومزاولة التمارين الرياضية ومحاولة الوصول للوزن المثالي وعمل حمية غذائية،

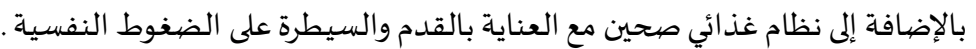

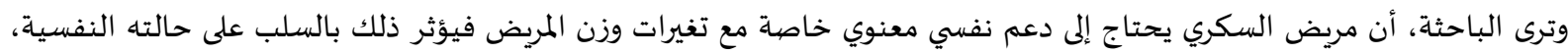
ويحاول العزلة والابتعاد عن الأشخاص حتى لا يتعرض لأي ، مضي مضايقات.

الدراسـات السـابقة: أولاً: دراسـات تناولت اضطراب صورة الجسم وعلاقته ببعض المتغيرات النفسية وهي على النحو التالي من الأقدم للأحدث : دراسـة ( أبوت، Abbotit,2000): أجرى أبوت دراسته التي هدفت إلى التعرف على العلاقة بين اضطراب صهورة الجسم وعلاقتها بتقدير الذات،

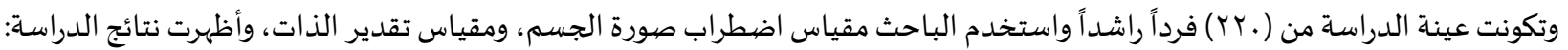

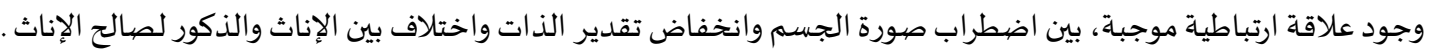
كما أجرى (هيود وأخرون، Heywoodet.al,2006) دراسـة هدفت إلى: فحص العلاقة بين اضطراب صورة الجسم واضطراب سلوك الأكل،

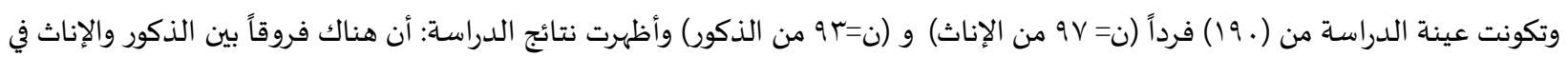

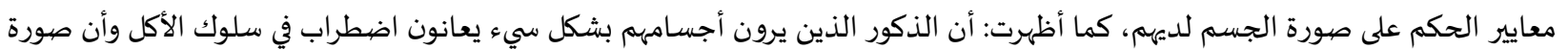

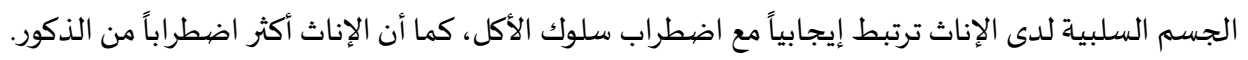

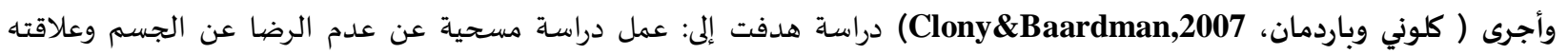

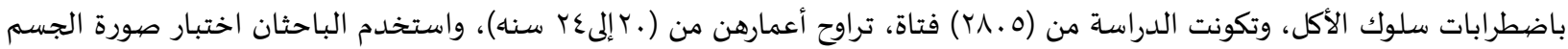

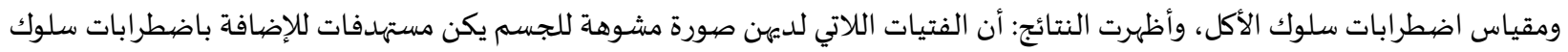

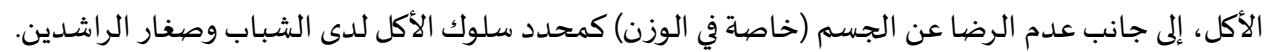

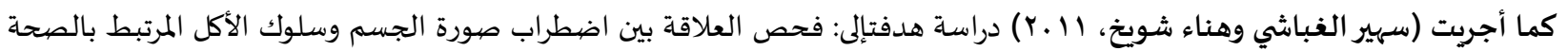
لدى طلاب الجامعة.

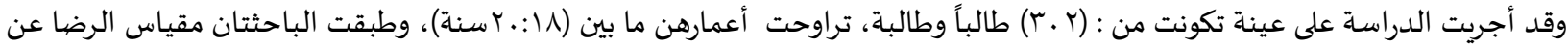
صهورة الجسم ومقياس المعرفة بسلوك الأكل المرتبط بالصحة، وأسفرت النتائج عن وجود ارتباط إيجابي بين صورة الجسم وسلوك الأبكل المرتبطة بالصحة . وأجرى (هورن وأخرون، Horne et al 2012 دراسة هدفت إلى: التعرف على علاقة اضطراب صورة الجسم لدى الإناث اللاتي يعانين من اضطرابات الأكل. 


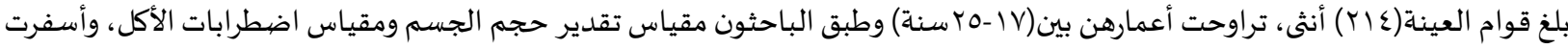

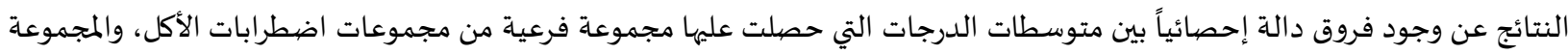

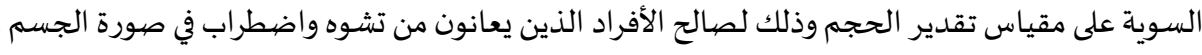

وأجرى ( رابى - جابلونسكا ، Rabe-Jablonska,2013) دراسة بعنوان: اضطراب صورة الجسم، لدى الطالبات اللاتي يعانين من فقدان التبان

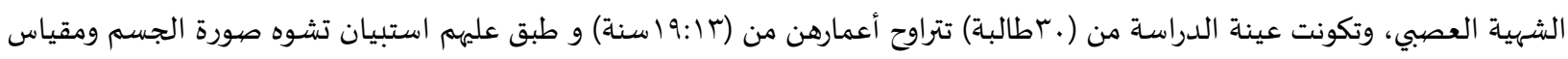

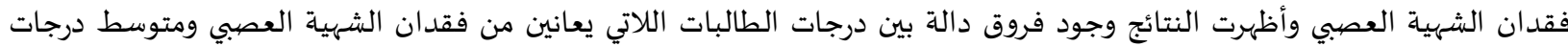

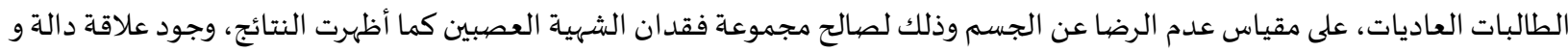

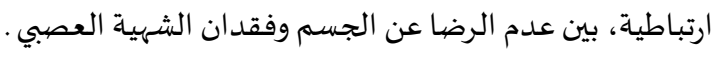

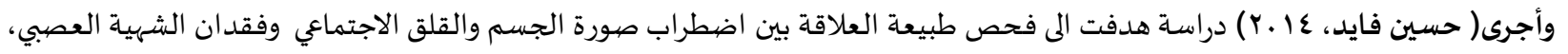

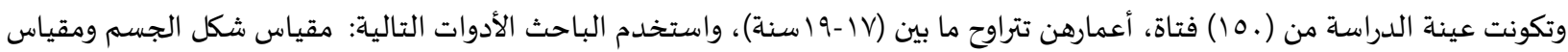

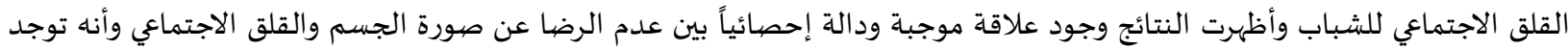

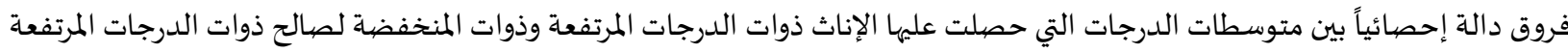
على مقياس فقدان الشهيية العصبي. وأجرى (سميتس وأخرون، smeets et al,2015) دراسة هدفت الى بحث اضطراب صورة الجسم لدى الإناث اللواتي يعانين من فقدان الشهية العصبي، وبلغت العينة (وسطالبة من الجامعة) وطبق الباحثون مقياس فقدان الشهية العصبي واستبيان اتجاهات الجسم، وأظهرت النتائج

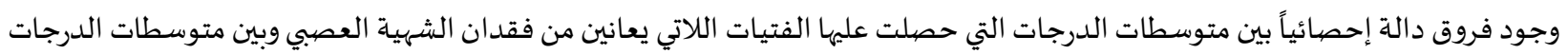

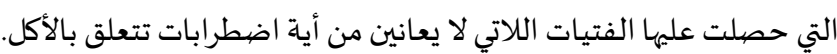

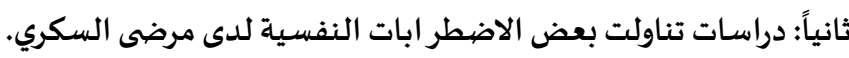

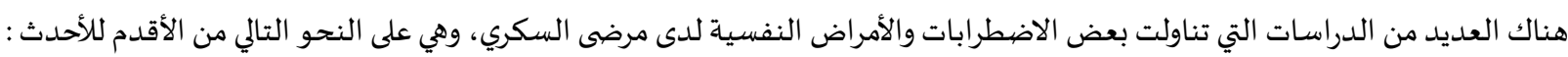

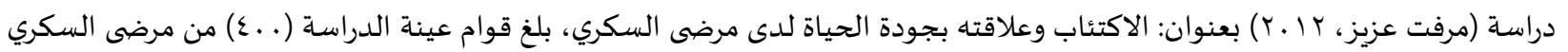

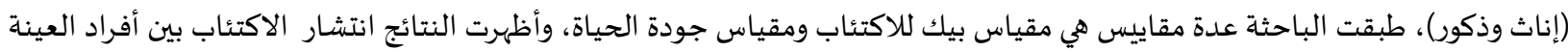

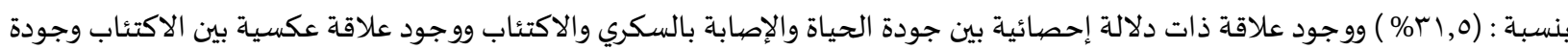
الحياة كما تبين أن الإناث أعلى من الذكور في مستوى الاكتئاب.

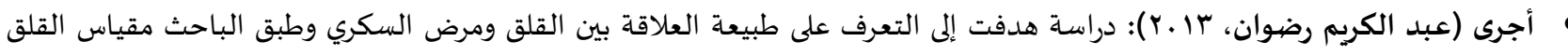

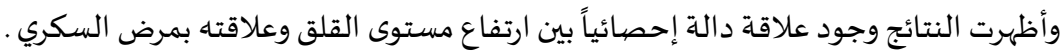

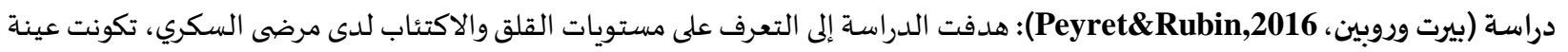

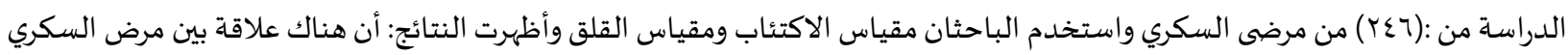
وخطورة حدوث اضطرابات نفسية، ووجود علاقة دالة إحصائياً بين مستويات القلق الماتيات المرتفعة وبين الاكتئاب.

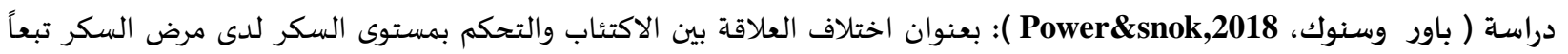

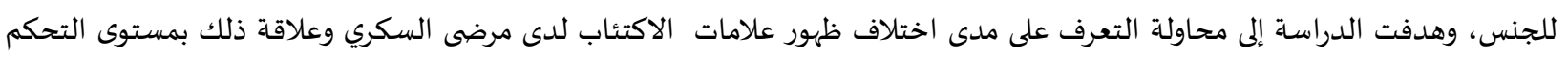

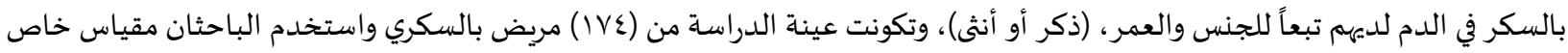

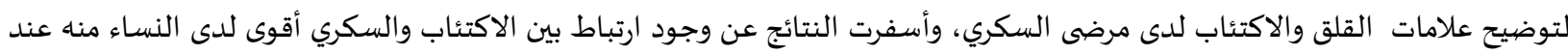

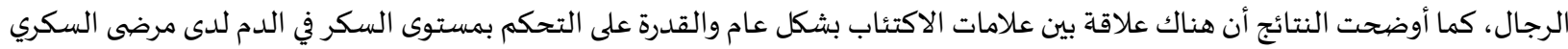

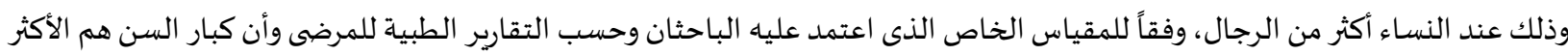
معاناتا من الشباب والراشدين.

\section{التعقيب على الدراسـات السـابقة:}

تناولت الدراسات السابقة صورة الجسم واضطرابها وعلاقها ببعض المتغيرات النفسية المختلفة مثل تقدير الذات، اضطراب سلوك الأكل، فقدان الشهية العصبي، القلق الاجتماعي، وتنوعت الموضوعات ولكن معظم الدراسات اعتمدت على حالات أسوياء ولم توجد دراسات إكلينيكية كمرض السكري أو القلب وغيره. 
الدراسات التي تناولت مرض السكري، تناولت متغيرات نفسية عديدة وتنوعت موضوعاتها منها جودة الحياة لدى مرضى السكري، القلق،

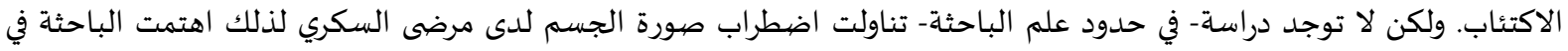

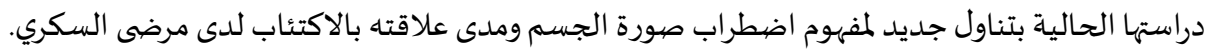

فروض الدراسة:

ا. توجد فروق د الة إحصائياً بين متوسطي درجات أفراد عينة الدراسـ(ذكور-إناث) لدى مرضى السكري على مقياس اضطراب الجسم.

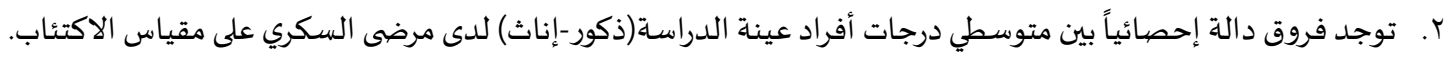

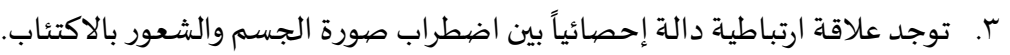
ع. تختلف متوسطات درجات عينة الدراسة على مقياس اضطراب صهورة الجسم ومقياس الاكتئاب باختلاف العمر.

$$
\text { أولاً: منهراء الدراسة: الدراسة: }
$$

اعتمدت الدراسة على المنهج الوصفي الارتباطي الذى يهتم بوصف الظاهرة وتحليل المعلومات والبيانات وتفسيرها في ضوء المتغيرات ذات

$$
\text { العلاقة و المنهج الوصيفي هو الأكثر مناسبة لمثل هذه الدراسـة. }
$$

ثانياً: عينة الدراسـة:

أجريت الدراسة على عينة بلغ قوامها (79) مريضا من مرضى السكري المترددين على وحدة العناية بمرضى السكري بمستشفى (الملك فهد

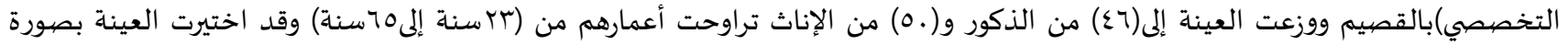
عشوائية من المستشفى.

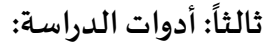
اشتملت الدراسة على الأدوات التالية:

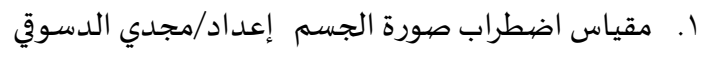

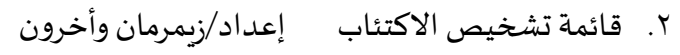

$$
\text { العرض التفصيلي لمقياس اضطراب صورة الجسم: }
$$

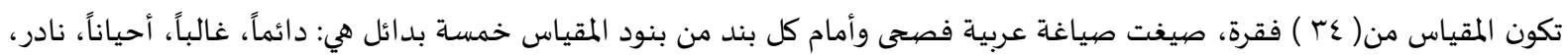

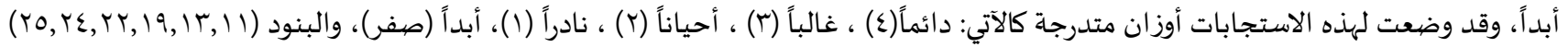

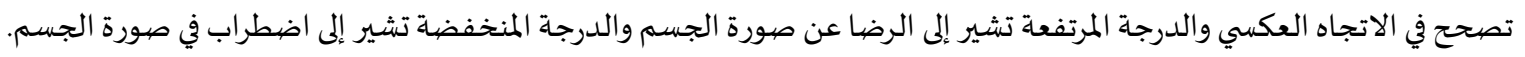

$$
\text { الخصيائص السيكومترية للمقياس: }
$$

صددق المقياس: تم حسـاب صدق المقياس باستخدام الصددق التلازمي: كما تم التحقق من الصيدق التلازمي للمقياس وذلك بحساب معامل

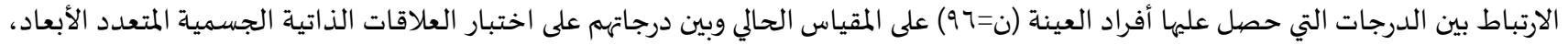

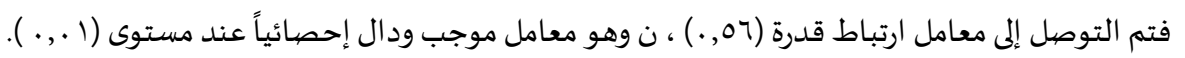

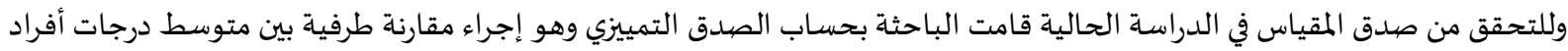
عينة الدراسة الذين حصلوا على درجات مرتفعة على مقياس اضطراب صورة الجسم ومتوسط درجات نظرائهم الذين حصلوا على درجات منخفضية

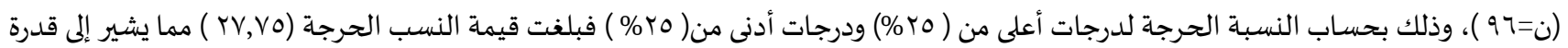
المقياسعلى التمييز بين مرتفعي ومنخفضي اضطراب صورة الجسم والجدول التالي يوضح ذلك: جدول (1): النسبة الحرجة لدلالة الفرق بين متوسط درجات مرضى السكري أعلى من (Y0\% )، ومتوسط درجات نظرائهم ضمن أدنى من ( \% \%) على مقياس

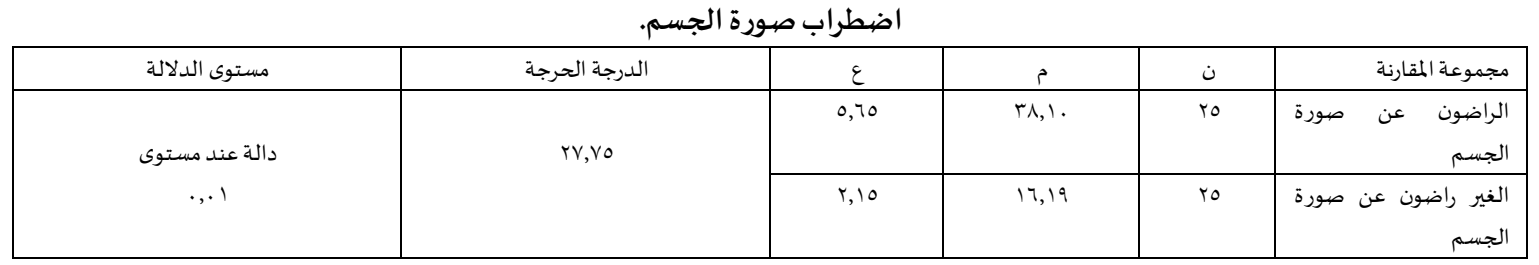


ثبات المقياس:

تم حساب ثبات المقياس طريقة إعادة الإجراء: تم تطبيق المقياس على مجموعة كلية من ( .0 ) طالبة من طالبات الجامعة ثم أعيد تطبيقه مرة أخرى على نفس

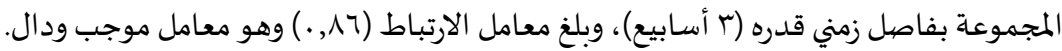
وقد أجرت الباحثة في دراستها الحالية لحساب ثبات مقياس اضطراب صهورة الجسم طريقة التطبيق ثم إعادة التطبيق للمقياس على عينة قوامها

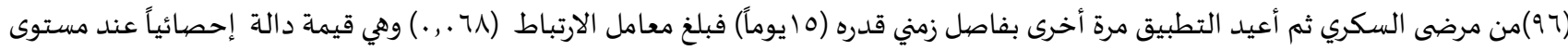

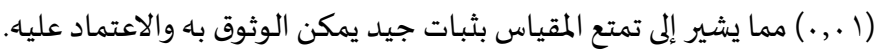

وصف قائمة تشخيص الاكتئاب:

أعد المقياس (زيمرمان وأخرون ZZimmerman,et al ع . . ) وذلك لقياس اضطراب الاكتئاب طبقاً لمعايير الدليل التشخيصي الرابع المعدل

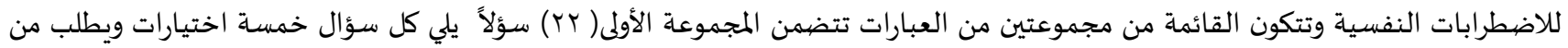

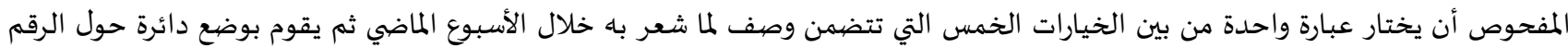

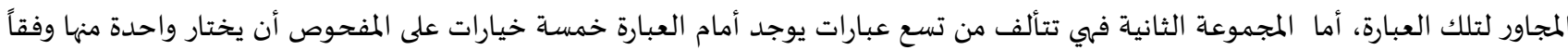

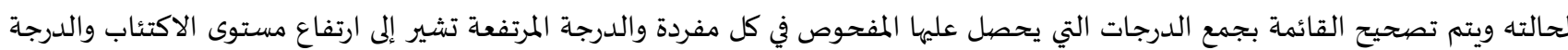
المنخفضية تشير إلى انخفاض مستوى الاكتئاب لدى المفحوص.

الخصيائص السيكومترية للقائمة:

$$
\text { صدق القائمة: }
$$

ولحساب صيدق القائمة قامت الباحثة بعرضها على (. () من الأساتذة المحكمين من أساتذة علم النفس والصحة النفسية، وذلك لتحديد مدى مناسبة العبارات وقد وصلت نسبة الاتفاق إلى (1)\% على جميع الفقرات وأن المقياس مناسب.

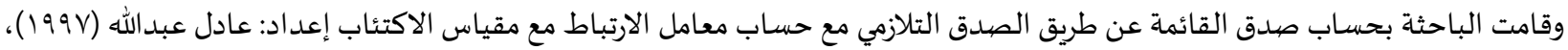

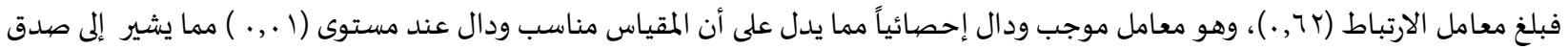
تلازمي مرتفع للقائمة. ثبات القائمة:

تم حساب ثبات القائمة باستخدام طريقة إعادة الإجراء على عينة قوامها ( إع ) سيدة ثم أعيد تطبيقها مرة أخرى على نفس المجموعة بفاصل

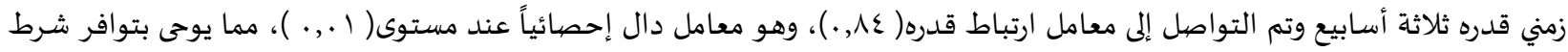

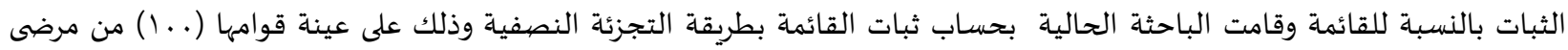

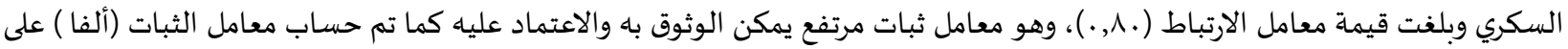

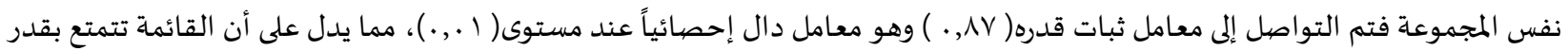
كبير من الثبات.

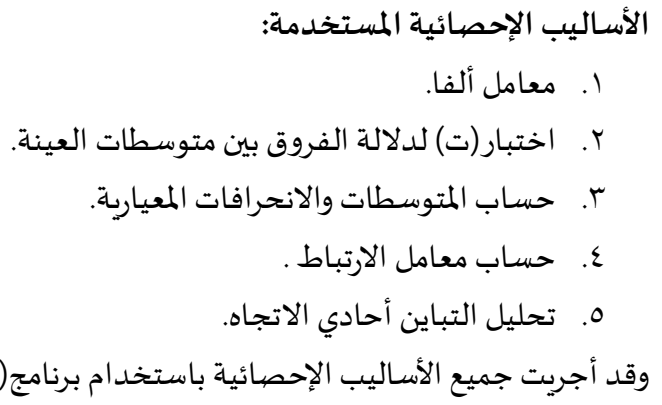

تفسير نتائج الدراسة ومناقشتها:

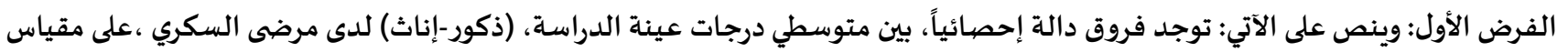
اضطراب صورة الجسم. 
وللتحقق من صحة هذا الفرض، تم حساب المتوسطات الحسابية وقيمة (ت) ،والجدول رقم (Y) يوضح ذلك

جدول(Y): يوضح قيمة (ت) لدلالة الفروق بين متوسطي عينة الدراسة (ذكور -إناث) على مقياس اضطراب صهورة الجسم

\begin{tabular}{|c|c|c|c|c|c|c|}
\hline مستوى الدلالة & قيمة (ت) & الإنحراف المعياري & المتوسط & ن & المجموعات & المتغير \\
\hline \multirow{2}{*}{ دال عند مستوى } & \multirow[t]{2}{*}{$\varepsilon, \Lambda T$} & $0,1 T$ & rr,q. & $\varepsilon 7$ & ذكور & مقياس اضطراب \\
\hline & & $r, r$. & $T V, 10$ & 0. & إناث & صورة الجسم \\
\hline
\end{tabular}

يتضح من جدول رقم(Y) وجود فروق دالة إحصائياً بين متوسطي درجات أفراد عينة الدراسة(الذكور- الإناث) على مقياس اضطراب صورة الجسم لصالح الإناث حيث نجد أن متوسطي درجات الإناث أقل من الذكور بفروق دالة إحصائياً وبذلك يتضح أن الإناث أكثر اضطراباً من الذكور، ولذلك سجلوا متوسط أدنى من متوسط الذكور. وترى الباحثة أن السبب في أن الإناث أعلى من الذكور هو الاهتمام الزائد من الإناث بكل برامج الموضية والاهتمام بالنحافة والرشاقة أكثر

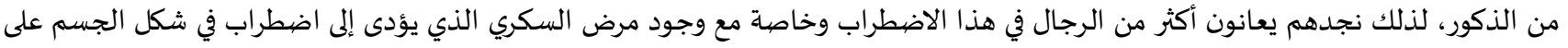

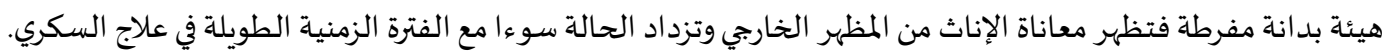

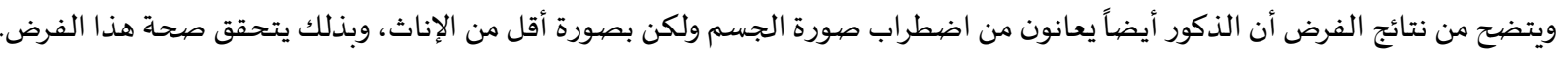
وتتفق نتائج هذا الفرض مع نتائج دراسة ( أبوت،

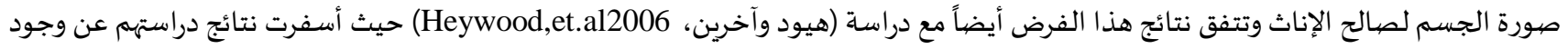

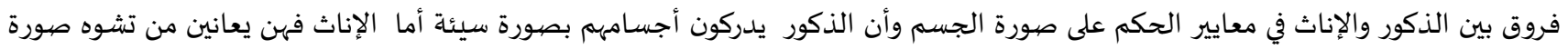

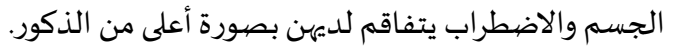
الفرض الثاني: توجد فروق دالة إحصيائياً، بين متوسطي درجات أفراب أفراد عينة الدراسة (ذكور-إناث) لدى مرضى السكري على على مقياس الاكتئاب. وللتحقق من صحة هذا الفرض تم حساب المتوسطات وقيمة (ت)، والجدول رقم (r) يوضح ذلك

جدول رقم (ץ): يوضح قيمة (ت) لدلالة الفروق بين متوسطي درجات عينة الدراسة (ذكور - إناث) على قائمة الاكتئاب

\begin{tabular}{|c|c|c|c|c|c|c|}
\hline مستوى الدلالة & قيمة (ت) & الانحراف المعياري & المتوسط & $\dot{ن}$ & المجموعات & المتغير \\
\hline \multirow{2}{*}{ دال عند مستوى } & \multirow[t]{2}{*}{ r,Ar } & 0,11 & $r 9, .7$ & $\varepsilon 7$ & ذكور & مقياس اضطراب \\
\hline & & $7, \pi$ & MT, Ir & 0. & إناث & صورة الجسم \\
\hline
\end{tabular}

يتضح من خلال جدول رقم (ץ) أنه يوجد فروق دالة إحصائياً بين متوسطي درجات عينة الدراسة (ذكور - إناث) مرضى السكري على مقياس

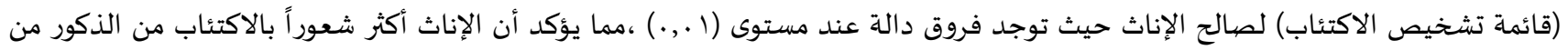
مرضى السكري.

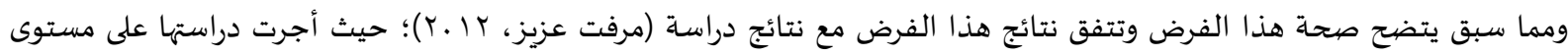

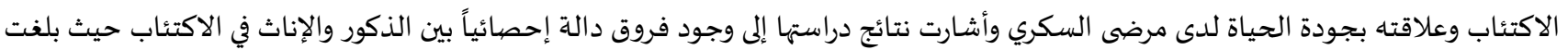

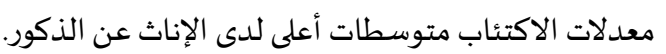

وترى الباحثة أن نتائج هذا الفرض نتائج منطقية؛ حيث نجد أندات النات مرض الاكتئاب يصيب الإناث بنسبة أعلى من الذكور؛ ويرجع ذلك لطبيعة

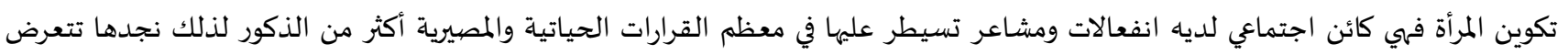

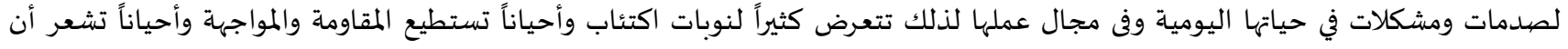

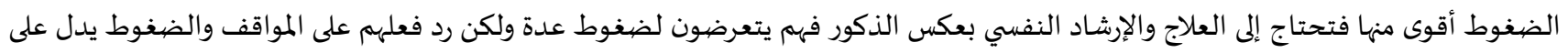
القوة وعدم الوقوع فريسة للمرض النفسي وهذا لا يمنع أن كثيراً من الذكور يتعرضون للأعراض.

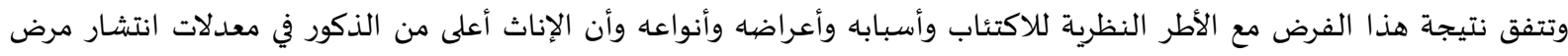

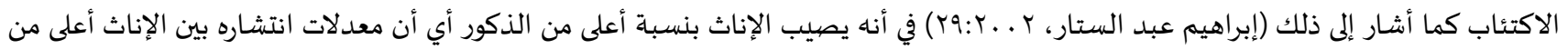

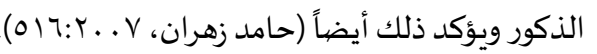
يتضح مما سبق، أن الاكتئاب خبرة إنسانية عامة يمر بها الفرد خلال مراحل حياته ولكن هذه الخبان الخبرة ليس شرطاً أن تتفاقم ويصل لحد

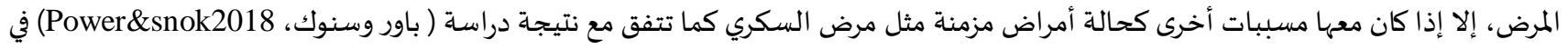

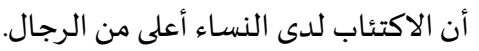
الفرض الثالث: وينص على الآتي: توجد علاقة ارتباطية دالة إحصيائياً بين اضطراب صيورة الجسم والاكتئاب. 
وللتحقق من صحة هذا الفرض تم حساب معامل الارتباط بين اضطراب صورة الجسم والاكتئاب، والجدول رقم (ع) يوضح ذلك

\begin{tabular}{|c|c|c|}
\hline مستوى الدلالة & معامل الارتباط باضطراب صورة الجسم & 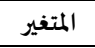 \\
\hline دالة عند مستوى ا .., . & $\cdot, \lambda r$ & الاكتئاب \\
\hline
\end{tabular}

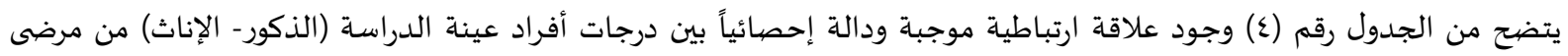

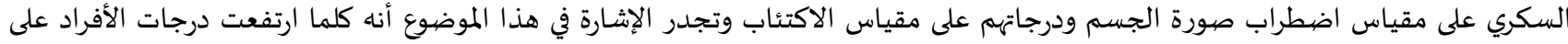

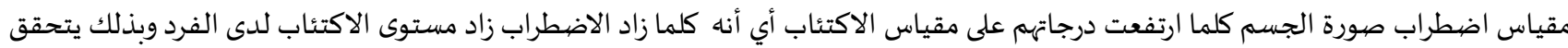

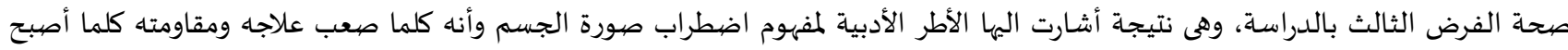
المريض يشعر بالإحباط و الاكتئاب. الفرض الر ابع: وينص على الآتي: تختلف متوسطات درجات عينة الدراسة على مقياس اضطراب صورة الجسم وقائمة تشخيص الاكتئاب

باختلاف العمر. وللتحقق من صحة هذا الفرض تم تطبيق تحليل التباين أحادي الاتجاه والجدول رقم (0) يوضح ذلك

جدول(0): تحليل التباين بين متوسطات أفراد العينة باختلاف العمر

\begin{tabular}{|c|c|c|c|c|c|}
\hline مستوى الدلالة & قيمة (ف) & متوسطات المربعات & درجة الحرية & مجموع المربعات & مصدر التباين \\
\hline \multirow[t]{3}{*}{ دالة عند مستوى ا .,. } & \multirow[t]{3}{*}{$\Lambda, 70$} & $V r \cdot, \cdot r$ & 0 & mo.,1. & بين المجموعات \\
\hline & & $\Lambda \cdot r, \varepsilon V$ & q. & VYMIT, \&O & داخل المجمموعات \\
\hline & & & 90 & V097T,00 & المجموع \\
\hline
\end{tabular}

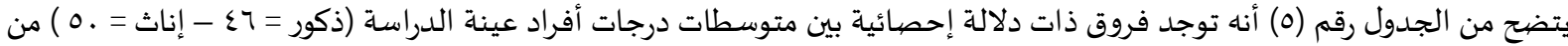

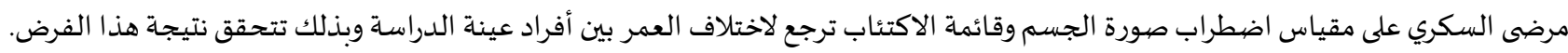

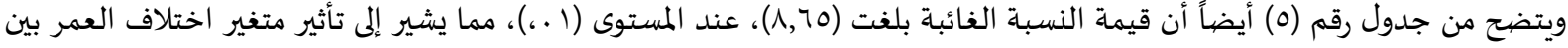

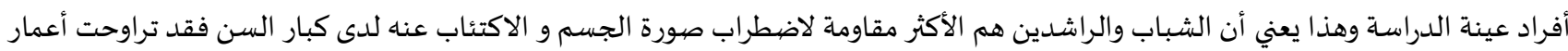

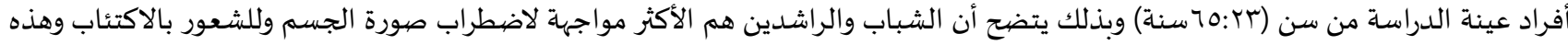

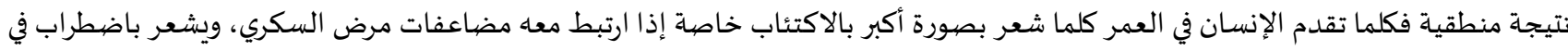

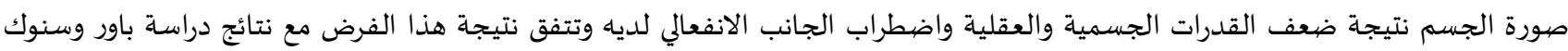

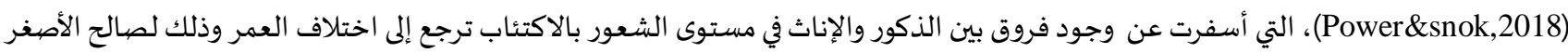

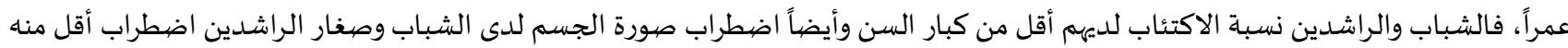

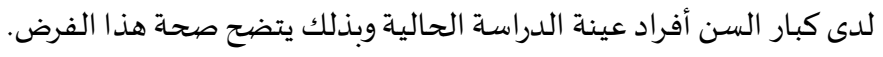

التوصيات:

تم صياغة التوصيات التالية في ضوء ما أسفرت عناه الدراسـة من نتائج:

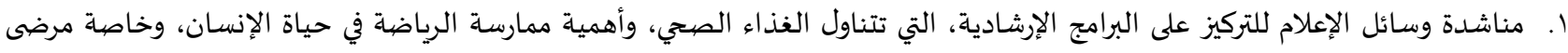

السكري.

r. عمل ندوات وورش عمل بوحدة متابعة مرضى السكري بالمستشفيات، الهدف منها توعية وإرشاد المرضى بمضاعفات السكري.

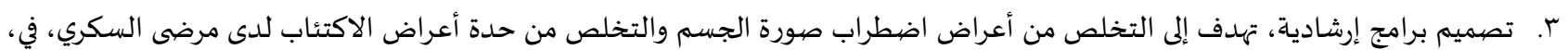
مختلف المراحل العمرية وخاصية الشباب. برابه 


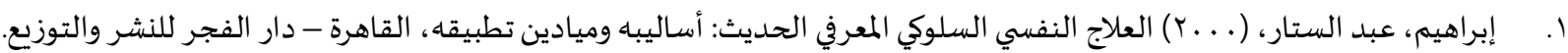

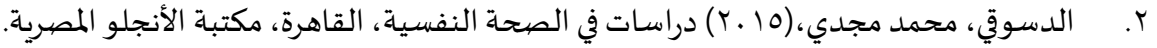

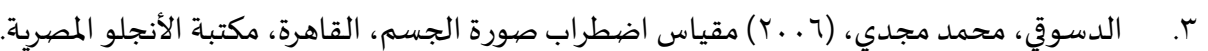

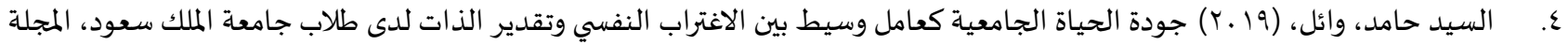

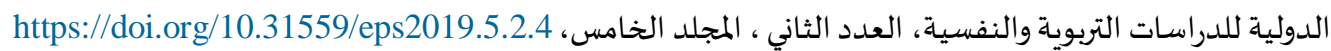

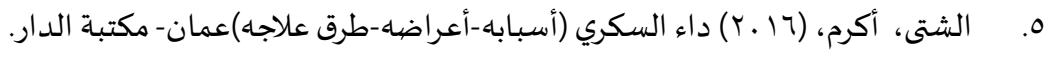

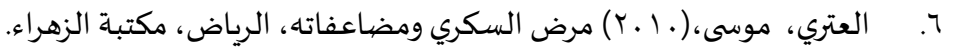

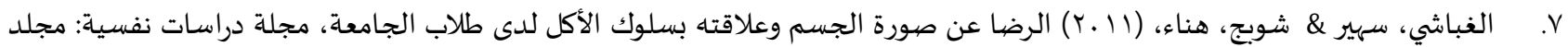

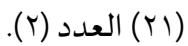

^. المعطي، هنا، (Y (Y) مرض السكري ، أنواعه وطرق علاجه، القاهرة، دار للطباعة.

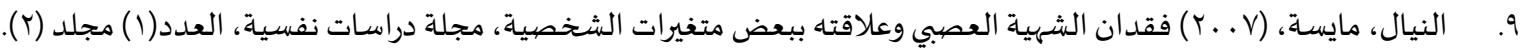

•l.

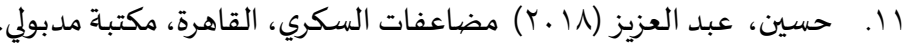

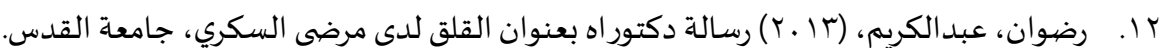

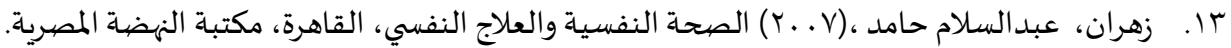

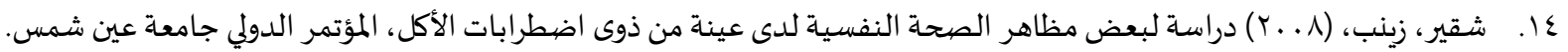

10. عبد الخالق، أحمد \& اليماني، مريم، (ع . . ب) فقدان الشهية العصبي، الكويت، مؤسسة الكويت للتقدم العلمي.

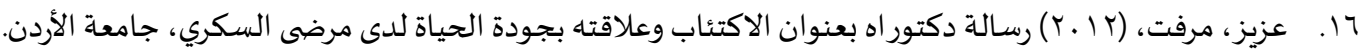

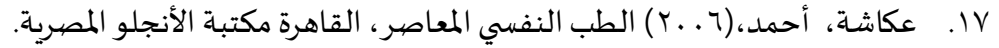

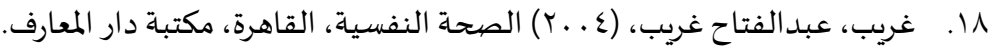

19. فايد، حسين، (عا .ب) صورة الجسم والقلق الاجتماعي وفقدان الشهية العصبي لدى الإناث المراهقات، المجلة المصرية للدراسات

النفسية، العددسז، ، المجلد9.

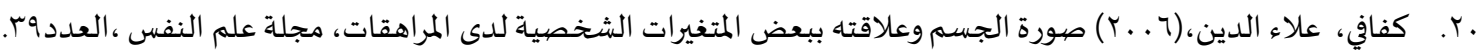

ا r. . محمد، عبدالله عادل، (199V) مقياس الاكتئاب، القاهرة، مكتبة الأنجلو المصرية.

ثانياً: المراجع الأجنبية:

[1] Abbotit. S, Perceived Body image and eating behavior in young adults with cystic fibrosis and their healthy, peers Journal of Behavioral medicine, 23(6)(2000).

[2] American obesity Association, obesity fast facts Available in New York :Macmillan, (2006)

[3] Baxter. B, Eating behavior in obese and Normal weight 11years old children, international journal of obesity and Related.161, (2009)

[4] Cloney. A\& Barman. J, Weight overestmion as an indicator of disorders eating behaviors among young woman in the united states, international journal of eating Disorders 40(5)(2007), 441-445, https://doi.org/10.1002/eat.20383

[5] Gove. p, Webster third new international Diaionary of the English Language unabridged, (2009)

[6] Hawroth. V, Different change of Body-images in patient with anorexia or bulimia nervosa during in patient psychosomatic treatment, Europeans Eating Disorders Review,14(2011) 
[7] Heywood et al, Negative Affect as mediator between dissatisfactions and extreme weight loss and muscle gain behaviors, Journal of health psychology,11(6)(2006), 833- 844, https://doi.org/10.1177/1359105306069077

[8] Horne. eta, Disturbed body image in patients with eating disorders, American Journal of psychiatry, (148) (2012).

[9] Jackson. A, Depression and Body image among woman with polycystic ovary syndrome, Journal of health psychology.11(4)(1995).

[10] Padesky, Subclinical eating disorders in female athletes woman and health, (3)(2004).

[11] Peter. N, The body image after breast cancer questionnaire: The design and testing of a disease specific measure, (2002)

[12] Peyret \& Rubin, The eating attitudes test: validation with Dsm-Iv eating disorder critters, Journal of personality Assessment, (3)(2016).

[13] Philips. M, Relation among weight control behaviors and eating attitudes social physique anxiety and fruit and vegetable consumption in Turkish Adolescents, (24)(1999)

[14] Power \& snok, Body shape concerns among adolescents, international Journal of Eating Disorders, (11)(2018).

[15] Rabe \& Gablonsk. J, The eating disorder continuum Comparison of depression and personality organization in anorexia nervosa Dissertation Abstracts international, (47)(2013).

[16] Rosen. J, Body image disturbances in eating disorders in new york Guilford press, (1996)

[17] Schilder. J, Anther optometry and Body image in a selected sample of adolescent girl's, international Journal medicine science, 154(1985)

[18] Smeets. ET. al, Body size categonzation in anorexia nervosa unsling a morphing instrument, international Journal of Eating Disorders, 25(4)(2015), https://doi.org/10.1002/(sici)1098-108x(199905)25:4\%3C451::aideat10\%3E3.3.co;2-s

[19] Snow. B, Emotion response pattern to Body weight related cues personality and social psychology Bulletin, (10)(2010).

[20] Vand bos. G, APA dictionary of psychology Washington, American psychology Association, (2008)

[21] Weise. H, Encyclopedia of psychology, New York John Wiley, (1)(2000)

[22] Zimmerman. et. al, Depression scale to diagnose major depressive disorder, Archives of General psychiatry, (43)(2004). 


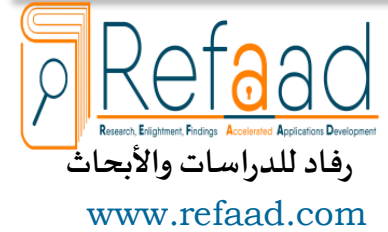

www.refaad.com
المجلة الدولية للدراسات التربوية والنفسية

e-ISSN 2520-4149, p-ISSN 2520-4130

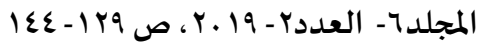

https://doi.org/DOI:10.31559/EPS2019.6.2.1
المجلة الدولية للدراسات

الثربوية والنفسية

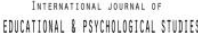

\title{
Body Image Disturbance and Relationship to the Feeling of Depression in Sample of Diabetes
}

\section{Lulua Saleh Al Rasheed}

Associate Professor, Department of Psychology, Faculty of Education, Alqassim University- KSA lolo2-222@ hotmail.com

\begin{abstract}
The present study aimed to detect the relationship between the disorder of the body image and the feeling of depression in a sample of diabetic patients, the sample of the study consisted of (96) diabetic patients in King Fahd Specialist Hospital in Buraidah in Al-Qassim region(46 males, 50 females), according to them The results of the study showed a significant correlation between body image disorder and the feeling of depression, the results also showed that females are more disturbed than males in the image of the body and they are more depressed than Males, also found significant differences Between the mean scores of the study sample (males - females) of diabetics on the body image disorder scale and depression list due to the age difference among the study sample.
\end{abstract}

Keywords: body image disorder; depression; diabetes

\section{References:}

[1] 'bdạlkhạlq. Ạ̉ḥmd \& Ạlymạny. Mrym, Fqdạn Ạlshhhyh Ạl'ṣby, Ạlkwyt, Mw̉ssẗ Ạlkwyt Lltqdm Ạl'lmy, (2004)

[2] 'kạsḩa. Ạhmmd, Ạlțb Ạlnfsy Ạlm 'ạṣr, Ạlqạhrh Mktbë Ạlạ̉njlw Ạlmṣryh, (2006)

[3] Ạl'try. Mwsa, Mrḍ Ạlskry Wmḍạ fạth, Ạlryạạ, Mktbë Ạlzhrạ’, (2010)

[4] 'zyz. Mrft, Rsạlẗ Dktwrạh B'nwạn Ạlạktỷạb W'lạqth Bjwdẗ Ạlhỵặ Lda Mrḍ̂y Ạlskry, Jạm đ̈ Ạlạ̉rdn, (2012)

[5] Abbotit. S, Perceived Body image and eating behavior in young adults with cystic fibrosis and their healthy, peers Journal of Behavioral medicine, 23(6)(2000).

[6] Abrạhym. 'bd Ạlstạr, Ạl'lạj Ạlnfsy Ạlslwky Ạlm rfy Ạlḥdytḥ: Ạ̉sạlybh Wmyạdyn Tṭbyqh, Ạlqạhrh Ḋạr Ạlfjr Llnsḥr Wạltwzy', (2000)

[7] American obesity Association, obesity fast facts Available in New York :Macmillan, (2006)

[8] Baxter. B, Eating behavior in obese and Normal weight 11years old children, international journal of obesity and Related.161, (2009)

[9] Cloney. A\& Barman. J, Weight overestmion as an indicator of disorders eating behaviors among young woman in the united states, international journal of eating Disorders 40(5)(2007), 441-445, https://doi.org/10.1002/eat.20383

[10] Ạldswqy. Mḥmd Mjdy, Drạsạt Fy Ạlṣḥh Ạlnfsyh, Ạlqạhrh, Mktbë Ạlạ̉njlw Ạlmṣryh, (2015) 
[11] Ạldswqy. Mḥmd Mjdy, Mqyạs Ạḍtrạb Șwrẗ Ạljsm, Ạlqạhrh, Mktbë Ạlạ̉njlw Ạlmṣryh, (2006)

[12] Fạyd. Ḥsyn, Ṣwrẗ Ạljsm Wạlqlq Ạlạjtmạ y Wfqdạn Ạlsḥhyh Ạl'ṣby Lda Ạlạ̣ạtḥ Ạlmrạhqạat, Ạlmjlh Ạlmșryh Lldrạsạt Ạlnfsyh, 9(23)(2014)

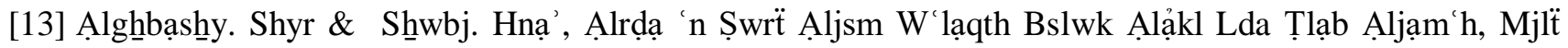
Drạsạt Nfsyh, 21(2)(2011)

[14] Gḥryb. 'bdạlftạh Gḥryb, Ạlṣḥh Ạlnfsyh, Ạlqạhrh, Mktbë Dạr Ạlm ậrf, (2004)

[15] Gove. p, Webster third new international Diaionary of the English Language unabridged, (2009)

[16] Hawroth. V, Different change of Body-images in patient with anorexia or bulimia nervosa during in patient psychosomatic treatment, Europeans Eating Disorders Review,14(2011)

[17] Heywood et al, Negative Affect as mediator between dissatisfactions and extreme weight loss and muscle gain behaviors, Journal of health psychology,11(6)(2006), 833- 844, https://doi.org/10.1177/1359105306069077

[18] Horne. eta, Disturbed body image in patients with eating disorders, American Journal of psychiatry, (148) (2012)

[19] Ḥsyn. 'bd Ạl'zyz, Mḍạ fạt Ạlskry, Ạlqạhrh, Mktbë Mdbwly, (2018)

[20] Jackson. A, Depression and Body image among woman with polycystic ovary syndrome, Journal of health psychology.11(4)(1995)

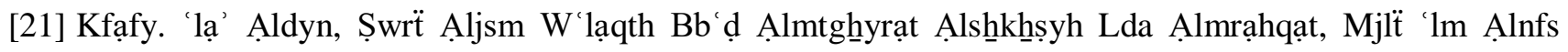
,(39)(2006)

[22] Ạlm ‘ṭy. Hnạ, Mrḍ Ạlskry,Ạ̉nwạ ‘h Wṭrq 'lạjh, Ạlqạhrh, Dạr Llțbạ ho, (2016)

[23] Mḥmd. 'bdạllh ‘ạdl, Mqyạs Ạlạktỵạb, Ạlqạhrh, Mktbë Ạlạ̉njlw Ạlmṣrygh, (1997)

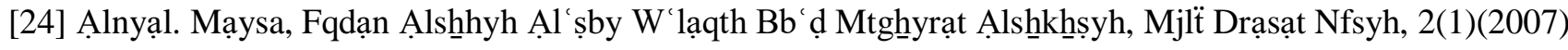

[25] Padesky, Subclinical eating disorders in female athletes woman and health, (3)(2004).

[26] Peter. N, The body image after breast cancer questionnaire: The design and testing of a disease specific measure, (2002)

[27] Peyret \& Rubin, The eating attitudes test: validation with Dsm-Iv eating disorder critters, Journal of personality Assessment, (3)(2016).

[28] Philips. M, Relation among weight control behaviors and eating attitudes social physique anxiety and fruit and vegetable consumption in Turkish Adolescents, (24)(1999)

[29] Power \& snok, Body shape concerns among adolescents, international Journal of Eating Disorders, (11)(2018).

[30] Rabe \& Gablonsk. J, The eating disorder continuum Comparison of depression and personality organization in anorexia nervosa Dissertation Abstracts international, (47)(2013)

[31] Rḍwạn. 'bdạlkrym, Rsạlẗ Dktwrạh B'nwạn Ạlqlq Lda Mrḍ̣ Ạ Alskry, Jạm‘̋̈ Ạlqds, (2013)

[32] Rosen. J, Body image disturbances in eating disorders in new york Guilford press, (1996) 
[33] Schilder. J, Anther optometry and Body image in a selected sample of adolescent girl's, international Journal medicine science, 154(1985)

[34] Ạlshnta. Ạ̉krm, Dạ’ Ạlskry (Ạ̉sbạbh-Ạ̉ rạ̣hh-Ṭrq 'lạjh)'mạn- Mktbë Ạldạr, (2016)

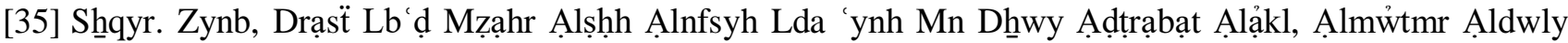
Jạm đ̈ 'yn Shms, (2008)

[36] Smeets. ET. al, Body size categonzation in anorexia nervosa unsling a morphing instrument, international Journal of Eating Disorders, 25(4)(2015), https://doi.org/10.1002/(sici)1098-108x(199905)25:4\%3C451::aideat10\%3E3.3.co;2-s

[37] Snow. B, Emotion response pattern to Body weight related cues personality and social psychology Bulletin, (10)(2010).

[38] Ạlsyd Ḥạmd. Wạyll, Jwdë Ạlhỵạh Ạljạm yh K’ạml Wsyṭ Byn Ạlạghnhtrạb Ạlnfsy Wtqdyr Ạldhạat Lda Ṭlạb Jạm ‘̈ Ạlmlk S'wd, Ạlmjlh Ạldwlyh Lldrạsạt Ạltrbwyh Wạlnfsyh, 5(2)(2019) https://doi.org/10.31559/eps2019.5.2.4

[39] Vand bos. G, APA dictionary of psychology Washington, American psychology Association, (2008)

[40] Weise. H, Encyclopedia of psychology, New York John Wiley, (1)(2000)

[41] Ạlywsf. Kḥlyl, Dạ’ Ạlskry, 'mạn, Mktbë Ạlsḥrq, (2017)

[42] Zhrạn. 'bdạlslạm Ḥạmd, Ạlșḥh Ạlnfsyh Wạl' lạj Ạlnfsy, Ạlqạhrh, Mktbë Ạlnhụh Ạlmṣryh, (2007)

[43] Zimmerman. et. al, Depression scale to diagnose major depressive disorder, Archives of General psychiatry, (43)(2004). 